\title{
Isolation and characterization of an osmotic stress and ABA induced histone deacetylase in Arachis hygogaea
}

\section{OPEN ACCESS}

Edited by:

Raúl Alvarez-Venegas,

Centro de Investigación y de Estudios Avanzados del IPN, Mexico

Reviewed by:

Gong-yin Ye,

Zhejiang University, China Keqiang Wu,

National Taiwan University, Taiwan

Xuncheng Liu,

South China Botanical Garden,

Chinese Academy of Sciences, China

${ }^{*}$ Correspondence:

Ling Li,

Guangdong Provincial Key Laboratory of Biotechnology for Plant Development, School of Life Sciences,

South China Normal University, No. 55, Zhongshan Avenue West, Tianhe District, Guangzhou 510631

China

liling502@126.com

${ }^{\dagger}$ These authors have contributed equally to this work.

Specialty section:

This article was submitted to

Plant Biotechnology,

a section of the journal Frontiers in Plant Science

Received: 13 March 2015 Accepted: 25 June 2015 Published: 13 July 2015

Citation:

Su L-C, Deng B, Liu S, Li L-M, Hu B, Zhong Y-T and Li L (2015) Isolation and characterization of an osmotic stress and $A B A$ induced histone deacetylase in Arachis hygogaea.

Front. Plant Sci. 6:512.

doi: 10.3389/fpls.2015.00512
Liang-Chen Su ${ }^{\dagger}$, Bin Deng ${ }^{\dagger}$, Shuai Liu, Li-Mei Li, Bo Hu, Yu-Ting Zhong and Ling Li *

Guangdong Provincial Key Laboratory of Biotechnology for Plant Development, School of Life Sciences, South China Normal University, Guangzhou, China

Histone acetylation, which together with histone methylation regulates gene activity in response to stress, is an important epigenetic modification. There is an increasing research focus on histone acetylation in crops, but there is no information to date in peanut (Arachis hypogaea). We showed that osmotic stress and ABA affect the acetylation of histone $\mathrm{H} 3$ loci in peanut seedlings by immunoblotting experiments. Using RNA-seq data for peanut, we found a RPD3/HDA1-like superfamily histone deacetylase (HDAC), termed AhHDA1, whose gene is up-regulated by PEG-induced water limitation and $A B A$ signaling. We isolated and characterized $A h H D A 1$ from $A$. hypogaea, showing that AhHDA1 is very similar to an Arabidopsis HDAC (AtHDA6) and, in recombinant form, possesses HDAC activity. To understand whether and how osmotic stress and ABA mediate the peanut stress response by epigenetics, the expression of AhHDA1 and stress-responsive genes following treatment with $P E G, A B A$, and the specific HDAC inhibitor trichostatin A (TSA) were analyzed. AhHDA1 transcript levels were enhanced by all three treatments, as was expression of peanut transcription factor genes, indicating that AhHDA1 might be involved in the epigenetic regulation of stress resistance genes that comprise the responses to osmotic stress and ABA.

Keywords: epigenetics, ABA, osmotic stress, acetylation, HDAC, RNA-seq, TSA

\section{Introduction}

Plants respond to various abiotic stresses by altering the expression of many genes. Drought is one of the most significant of such abiotic stresses because it limits cell growth and development; consequently, plants have developed diverse strategies to cope with limited water availability (Jung et al., 2005). One such strategy is epigenetic modification of chromatin structure through posttranslational modification of histones, for example by acetylation and ubiquitination of lysine residues, methylation of arginine, and phosphorylation of serine or threonine (Henderson and Jacobsen, 2007; Kim et al., 2010). This regulates the expression of genes within the modified chromatin, thereby affecting plant growth and development (Lopez-Gonzalez et al., 2014; Zhang et al., 2014).

Histone acetylation is controlled by histone acetyltransferases (HATs) and histone deacetylases (HDAs or HDACs). In general, HATs transfer acetyl groups to core histone tails, thereby promoting transcription of target genes, whereas HDACs remove acetyl groups from the Lys residues of 
histone tails, resulting in the repression of gene transcription (Kurdistani and Grunstein, 2003). Plant HDACs are classified into three distinct families, namely RPD3/HDA1-like HDAs, SIR2-like HDAs, and HD2 proteins, based on sequence similarity, substrate specificity, and cofactor requirement (Pandey et al., 2002; Loidl, 2004; Fong et al., 2006; Zhong et al., 2013). Arabidopsis thaliana has 12 RPD3/HDA1 subfamily genes (HDA2, HDA5, HDA6, HDA7, HDA8, HDA9, HDA10, HDA14, HDA15, HDA17, HDA18, and HDA19) among 18 putative HDAC family genes (Ma et al., 2013). Of these, HDA6 has been reported to participate in jasmonic acid-mediated plant defense responses and to be involved in transgene silencing and the regulation of rRNA transcription (Murfett et al., 2001; Devoto et al., 2002; Tanaka et al., 2008); HDA19 is involved in jasmonic acid and ethylene signaling during the response to pathogens, and redundantly with HDA6 regulates the repression of embryonic properties during germination (Zhou et al., 2005; Tanaka et al., 2008); both up-regulation and down-regulation of HDA7 and HDA18 in Arabidopsis cause growth delays at different developmental stages (Cigliano et al., 2013; Liu et al., 2013); HDA9, which acts to oppose the effect of its homologs HDA6 and HDA19, is a negative regulator of germination in seedlings (van Zanten et al., 2014). Thus, these HDAs respond to environmental stress or participate in plant development.

HDAs function on various histone loci within chromatin and these can be detected by Western blot, chromatin immunoprecipitation (ChIP) assays or immunocytochemistry. Research in plants has focused on modifications of histones $\mathrm{H} 3$ and $\mathrm{H} 4$, which are involved in cell development, flowering, transposon repression and abiotic stress response (Zhao et al., 2014). In Arabidopsis, there is region-specific enrichment of $\mathrm{H} 3 \mathrm{~K} 23 \mathrm{ac}$ and $\mathrm{H} 3 \mathrm{~K} 27 \mathrm{ac}$ in the coding regions of the droughtresponsive genes $R D 29 B, R D 20$, and $R A P 2.4$, while enrichment of H3K4me3 and H3K9ac correlates with RD29A, RD29B, RD20, and RAP2.4 gene activation in response to drought stress (Kim et al., 2008). DREB1 (dehydration responsive element binding 1) proteins, have been shown to play an important role in the response of plants to low-temperature stress (Liu et al., 1998). During cold stress in rice, histone H3K9 acetylation is increased throughout the $800 \mathrm{bp}$ region of OsDREB1b, whereas $\mathrm{H} 3 \mathrm{~K} 14$ and $\mathrm{K} 27$ acetylation is biased more toward the core promoter and upstream region, respectively (Roy et al., 2014). Immunoblotting analysis shows that H3K9ac, H3K18ac, $\mathrm{H} 3 \mathrm{~K} 27 \mathrm{ac}$, and H4K5ac levels increase with the expression of HATs in response to drought treatment in rice leaves (Fang et al., 2014). In maize, H3K9ac, H4K5ac, and H4ac levels in the $Z m I C E 1$ and $Z m C O R 413$ promoter and coding regions increase with $Z m D R E B 1$ up-regulation on cold treatment (Hu et al., 2011). Thus, modifications in histone acetylation patterns in plants during stress treatment are associated with the expression of stress response genes.

Drought is one of the most growth-limiting factors for crops. In our previous research on the molecular consequences of environmental stress and abscisic acid (ABA) action in peanut (Arachis hypogaea), an economically important oiland protein-rich crop plant, we analyzed the role of droughtrelated genes under conditions of water limitation. AhNCED1 (9-cis-epoxycarotenoid dioxygenase) protein catalyzes the ratelimiting step in the ABA biosynthetic pathway in peanut, and its expression is up-regulated by dehydration and $\mathrm{ABA}$; furthermore, heterologous expression of AhNCED1 increases drought resistance in Arabidopsis (Wan and Li, 2005, 2006). In addition, we also found that $A h A R E B 1$, a gene which encodes a transcription factor (TF), was induced by ABA or drought (Li et al., 2013). Genes encoding stress-combative dehydrins, i.e., AhDHNs, were also upregulated by ABA and PEG (which imposes osmotic stress) in peanut leaves (Su et al., 2012). RNAseq results show that other TF-like genes (MYB92-like and WRKY33-like) participate in the early stages of the peanut response to ABA and osmotic stress (Li et al., 2014). However, whether any of these genes are involved in epigenetic regulation, specifically with respect to the osmotic stress response, is still unknown and there are very few reports of the relationship between osmotic stress, ABA signals and plant deacetylation in crops.

In this paper, histone acetylation status in peanut was found to be modified as part of the response to both ABA and PEG treatment. By reference to an RNA-seq database for peanut, we discovered a histone deacetylase 6-like gene that was upregulated by water deficit and ABA (Li et al., 2014), a result we confirmed by quantitative real-time PCR (qRT-PCR). This histone deacetylase sequence, termed AhHDA1, was isolated and its expression was analyzed to determine transcripts abundance in different tissues of peanut. The expression of AhHDA1 was compared to that of various drought resistance genes during osmotic stress and ABA treatment to attempt to understand the role of AhHDA1 under these conditions.

\section{Materials and Methods}

\section{Peanut Plants and Growth Conditions}

Seeds of peanut (Arachis hypogaea L. cv Yueyou 7) (Fang et al., 2007) were sown in pots with a potting mixture of vermiculite, perlite and soil (1: 1:1), and grown in a illumination incubator with $16 \mathrm{~h}$ of light from fluorescent and incandescent lamps $\left(200 \mu \mathrm{mol} \mathrm{m} \mathrm{m}^{-2} \mathrm{~s}^{-1}\right)$ at $26^{\circ} \mathrm{C}$ followed by $8 \mathrm{~h}$ of darkness at $22^{\circ} \mathrm{C}$. Plants were watered with half-strength Murashige and Skoog nutrient solution every other day (Wan and Li, 2005).

\section{Abiotic Stress and Hormone Treatments of Peanut Plants}

Four-leaf stage peanut seedlings were treated with PEG6000 (Roche) to simulate osmotic stress conditions, and ABA (Roche) and trichostatin A (TSA, Roche) were also applied exogenously for other treatments. After water had been removed by filter paper, the seedlings were harvested, rinsed with deionized water, and placed in beakers containing different solutions of PEG, $\mathrm{ABA}$, or TSA in deionized water. The seedlings were transferred to an illumination incubator $\left(26^{\circ} \mathrm{C}, 60 \%\right.$ moisture) under continuous light. PEG and ABA were applied at a concentration of $20 \%$ (w/v) and $100 \mu \mathrm{M}$, respectively (Wan et al., 2011). TSA was applied at a concentration of $1 \mu \mathrm{M}$. Control plants were planted in soil but not treated. Mock plants were placed in an equivalent volume of deionized water as experimental plants 
instead of ABA and TSA solutions. Control group and treated groups were also used for qRT-PCR and immunoblotting (see below for details). Peanut leaf samples $(100 \mathrm{mg}$ ) were taken at $0,1,2,5$, and $8 \mathrm{~h}$ and were maintained at $-70^{\circ} \mathrm{C}$ until further use.

\section{Protein Gel Electrophoresis and Immunoblotting}

Peanut leaves $(800 \mathrm{mg}$ ) were ground to a powder in liquid nitrogen and mixed to homogeneity in $1 \mathrm{ml}$ ice-cold extraction buffer 1 (10 mM potassium phosphate, $\mathrm{pH} 7.0,0.1 \mathrm{M} \mathrm{NaCl}$, $10 \mathrm{mM}$ beta-mercaptoethanol, $1 \mathrm{M}$ hexylene glycol) with protease
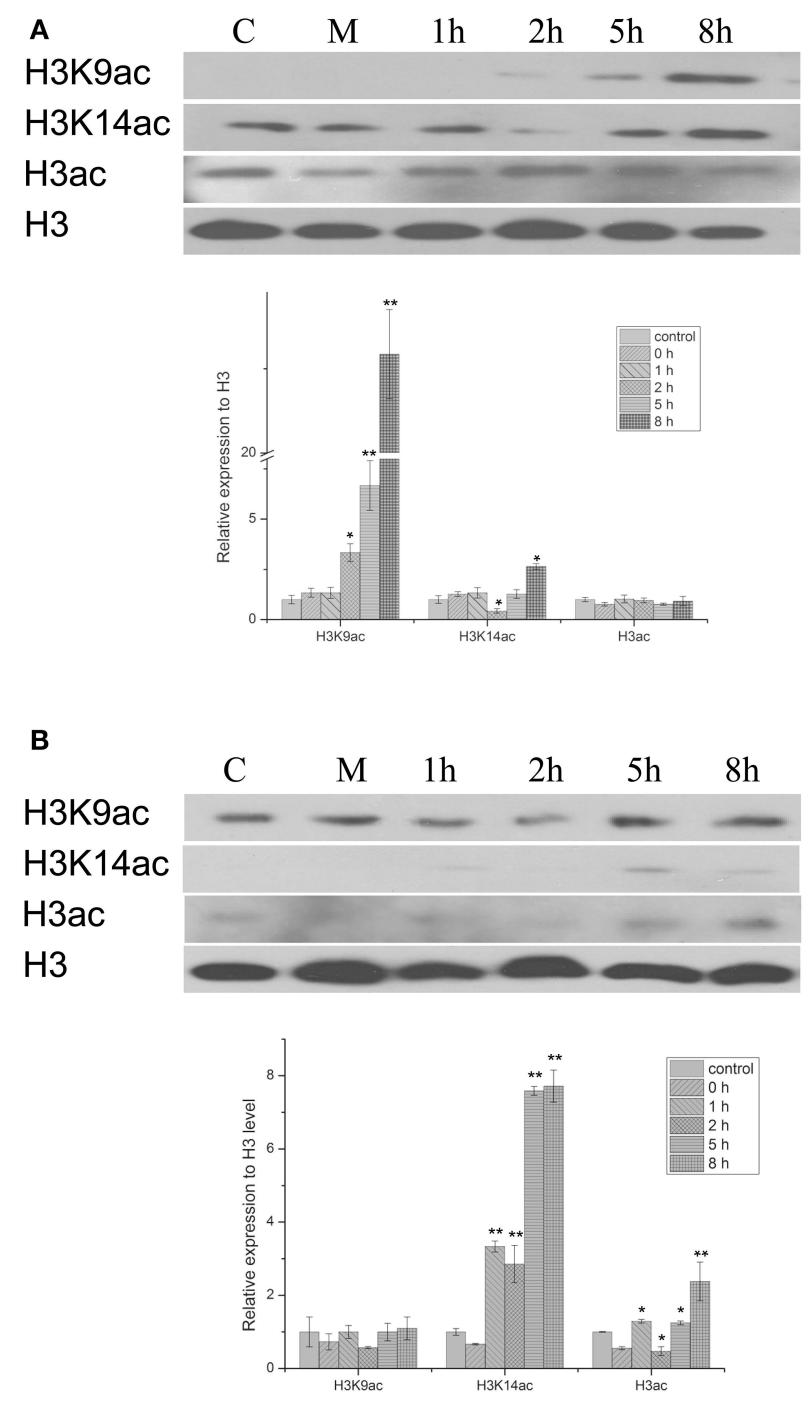

FIGURE 1 | Western blot showing the effect of PEG and HBA on histone $\mathrm{H} 3$ acetylation status in nuclear proteins from peanut leaves.

(A) $\mathrm{H} 3$ acetylation status in peanut leaves treated with 20\% (w/v) PEG. (B) H3 acetylation status in peanut leaves treated with $100 \mu \mathrm{M} \mathrm{ABC}$. C, control group; $\mathrm{M}$, Mock plants were placed in an equivalent volume of deionized water as experimental plants; $1-8 \mathrm{~h}$, time point after treatment. The experiments have been carried out at least three times. Each graph displays the mean and SD of three independent experiments. ${ }^{* *}$, different from control as revealed by $t$-test, $p<0.05 / 0.01$. inhibitor (Roche, catalog No. 06538304001). The extract was centrifuged at $13,000 \mathrm{rpm}$ for $10 \mathrm{~min}$ at $4^{\circ} \mathrm{C}$ and the supernatant was discarded. The pellet was resuspended gently in $0.5 \mathrm{ml}$ precooled buffer $2(10 \mathrm{mM}$ potassium phosphate, $\mathrm{pH} 7.0,0.1 \mathrm{M}$ $\mathrm{NaCl}, 10 \mathrm{mM}$ beta-mercaptoethanol, $1 \mathrm{M}$ hexylene glycol, $10 \mathrm{mM}$ $\mathrm{MgCl}_{2}, 0.5 \%$ Triton X-100) with protease inhibitor, centrifuged at $13,000 \mathrm{rpm}$ for $10 \mathrm{~min}$ at $4^{\circ} \mathrm{C}$ and the supernatant was discarded. The buffer 2 step was repeated until the supernatant after centrifugation was light green. Then the pellet was resuspended gently in $1 \mathrm{ml}$ pre-cooled buffer $3(10 \mathrm{mM}$ potassium phosphate, $\mathrm{pH} 7.0,0.1 \mathrm{M} \mathrm{NaCl}, 10 \mathrm{mM}$ beta-mercaptoethanol) with protease inhibitor, centrifuged at $13,000 \mathrm{rpm}$ for $10 \mathrm{~min}$ at $4^{\circ} \mathrm{C}$ and the supernatant was discarded. The nuclear pellet was resuspended gently in $0.5 \mathrm{ml}$ pre-cooled sonication buffer $(10 \mathrm{mM}$ potassium phosphate, $\mathrm{pH}$ 7.0, 0.1 M NaCl, $10 \mathrm{mM}$ EDTA $\mathrm{pH} 8.0,0.5 \%$ sarkosyl). The resuspended mixture was sonicated for $5 \mathrm{~min}$ on ice and sonicated samples were centrifuged at 13,000 rpm for $5 \mathrm{~min}$ at $4{ }^{\circ} \mathrm{C}$. The supernatant was transfer into a new tube and stored at $-70^{\circ} \mathrm{C}$.

The nuclear extract was suspended in $5 \times$ SDS PAGE loading buffer $(0.25 \mathrm{M}$ Tris-HCl, pH 6.8, 10\% SDS, 50\% glycerol, and $5 \%$ 2-mercaptoethanol). The concentration of protein samples was determined using a Bio-Rad protein assay kit (Bio-Rad, Hercules, CA, USA), loaded and run on $15 \%$ polyacrylamide gels, then gels were blotted onto a $0.22 \mu \mathrm{m}$ PVDF membrane. The membrane was blocked in Tris-buffered saline with $0.1 \%$ Tween 20 (TBST, pH 7.6) containing 5\% dry milk overnight and then incubated with $0.01-0.05 \mathrm{mg} / \mathrm{mL}$ of anti-histone $\mathrm{H} 3$ (Abcam, catalog no. ab1791), anti-acetyl-histone H3 (Abcam, catalog no. ab47915), anti-acetyl-histone H3K9 (Millipore, catalog no. 07-352) and anti-acetyl-histone H3K14 (Millipore, catalog no. 07-353) for $2 \mathrm{~h}$ at room temperature. After washing, the primary antibody was detected with secondary goat antirabbit alkaline phosphatase-coupled antibody (Millipore, catalog no. AP307A) at room temperature for $45 \mathrm{~min}$. Visualization was achieved using the ECL system (Millipore, catalog no. 345818).

\section{Isolation and Sequence Analysis of AhHDA1 from Arachis Hypogaea L.}

First-strand cDNA was synthesized by reverse transcription (RT) of $1 \mu \mathrm{g}$ of total RNA from peanut leaves, either untreated or treated for $5 \mathrm{~h}$ with $20 \%$ PEG 6000, using 200 units Superscript III Reverse Transcriptase (Invitrogen, catalog No. 18080) and 500 ng oligo-dT primer. The cDNA was used as the template for PCR using specific primers (ORF1-F: AAGTTGAAAACCCCAC ACCT; ORF1-R: CACCAAGCAGACTAAAGCAAAA) for the amplification of AhHDA1. These primers were designed to amplify the full length sequence of the AhHDA1 ORF. RT conditions were: $70^{\circ} \mathrm{C}$ for $10 \mathrm{~min}$, followed by $42^{\circ} \mathrm{C}$ for $1 \mathrm{~h}$, followed by $15 \mathrm{~min}$ at $70^{\circ} \mathrm{C}$. PCR amplification was performed as follows: $94^{\circ} \mathrm{C}$ for $5 \mathrm{~min}$, then 35 cycles of $94^{\circ} \mathrm{C}$ for $30 \mathrm{~s}, 55^{\circ} \mathrm{C}$ for $45 \mathrm{~s}$ and $72^{\circ} \mathrm{C}$ for $1 \mathrm{~min}$, then finally $72^{\circ} \mathrm{C}$ for $10 \mathrm{~min}$.

PCR fragments were gel purified with an Agarose Gel DNA Purification Kit (TaKaRa, catalog no. DV805A) and were ligated into the pMD 19-T Vector (TaKaRa, catalog no. 6013). Plasmids were isolated and were sequenced from both strands. Sequence 
A
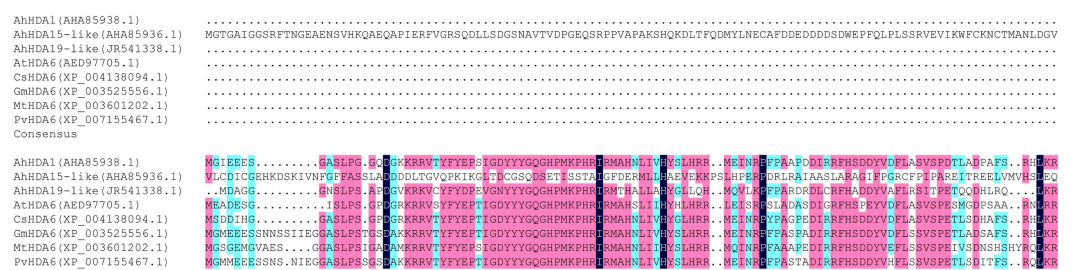

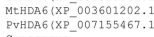

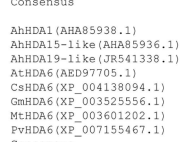

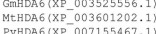
PvHDAG (XP_-007155467.
Consensus

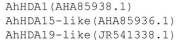

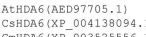

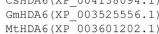

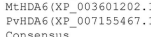

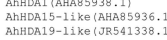
AtHDA6 (AED97705.1)
CSHDA6 (XP 004138094.

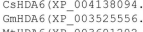
MtHDA6 (XP 003601202.1
PVHDA6 (XP_-007155467.1

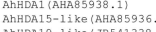
AhHDD19-1ike(JR541338.
AtHDA6 (AED97705.1) CSBDA6 (XP_004138094

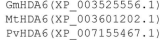
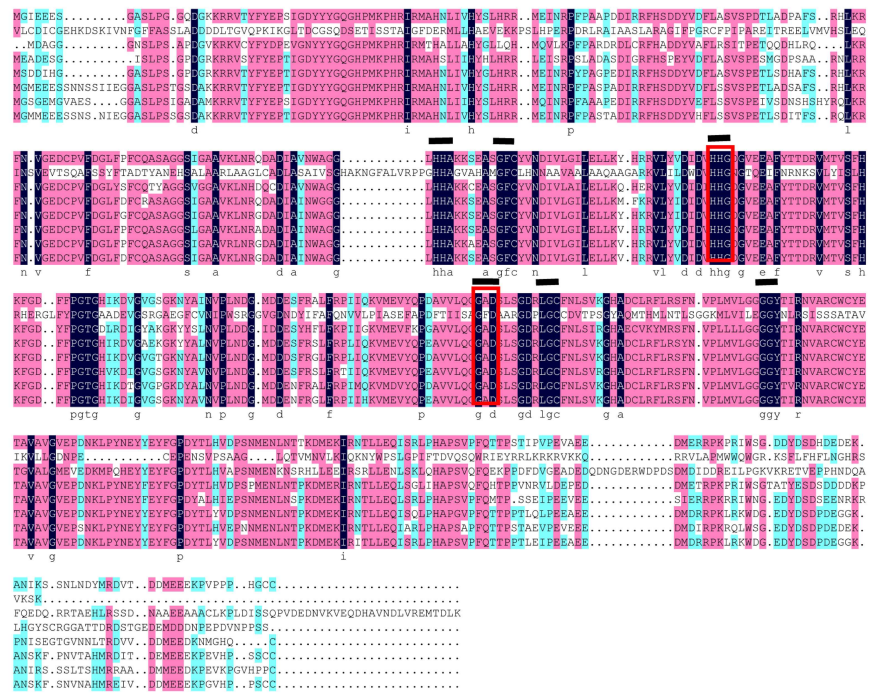

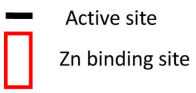

B

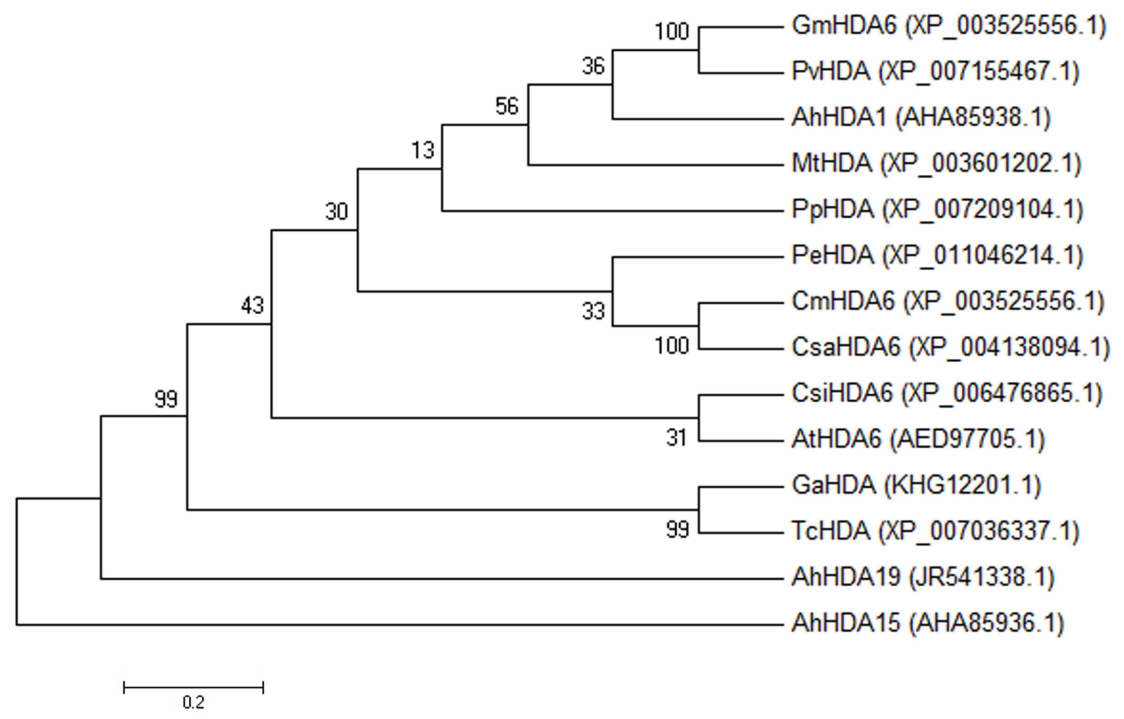

FIGURE 2 | Relatedness of peanut HDACs sequences to counterparts in other plants. (A) Alignment of deduced amino acid sequence of peanut HDACs with other plant HDAC sequences. The degree of similarity of the amino acid residues at each residues at each aligned position is shaded black, red, blue, in decreasing order. GenBank accession numbers for each aligned HDAC protein are indicated in parenthesis. (B) Phylogenetic analysis of amino acid sequences of AhHDA1 and other plant HDACs. A multiple sequence alignment was performed using Clustal $W$ and the phylogenetic tree was constructed via the Neighbor-Joining method in MEGA 4 software. Bootstrap values from 1000 replicates for each branch are shown. GenBank accession numbers: Glycine max HDA6 (XP 003525556.1), Phaseolus vulgaris HAD (XP_007155467.1), Arachis hypogaea HDA1 (JR541338.1), Medicago truncatula HDA (XP_003601202.1), Prunus persica HDA (XP_007209104.1), Populus euphartica HDA (XP_011046214.1). Cucumis melo HDA6 (XP_00864523.1), Cucumis sativas HDA6 (XP_004138094.1), Citrus sinensis HDA6 (XP_006476865.1), Arabidopsis thaliana HA6 (AED97705.1), Gossypium arboretum HDA (KHG12201.1), Theobroma cacao HDA (XP_007036337.1), Arachis hypogaea HDA19-like (AHA85936.1), Arachis hypogaea HDA15-like (AHA85936.1). The scale bar is 0.02 . 
analysis was performed using EditSeq software (Lasergene7.0). Computer analysis of the DNA and amino acid sequences was carried out using the BLAST program at the National Center for Biotechnology Information Services (http://www.Ncbi.Nlm. Nih.gov/BLAST). For phylogenetic analysis, we used neighborjoining (NJ) methods implemented using the full alignment program in DNAMAN software (Wan and $\mathrm{Li}, 2005$ ). 3D comparative protein structure models of peanut AhHDA1 were generated with the automatic modeling mode of SWISS-MODEL implemented on the SWISS-MODEL Workspace website (http:// swissmodel.expasy.org/) (Schwede et al., 2003; Arnold et al., 2006).

\section{Quantitative Real-time PCR (qRT-PCR)}

RNA extraction was carried out as described by Wan and Li (2005). Three biological replicate RNA samples of each time point and treatment were used for downstream applications. First-strand cDNAs, obtained using the Superscript III reverse transcriptase kit with $0.3 \mathrm{nmol}$ random 15 -mers for reverse transcription of $1 \mu \mathrm{g}$ RNA, were used as templates for qRTPCR. Aliquots of $1 \mu \mathrm{l}$ cDNA were then used for each RTqPCR reaction. Absolute QPCR SYBR Green ROX Mix (ABgene, catalog no. AB-4105) was used according to the manufacturer's instructions for quantification with the ABI PRISM 7300 Sequence Detection System (Applied Biosystems, UK). A melting curve confirmed single product amplification. Analysis of the raw data and calculation of the efficiency (E) for every single well was done using the software PCR Miner (Zhao and Fernald, 2005). Relative expression for each well was calculated as $(1+\mathrm{E})-$ CT (Muller et al., 2002). Expression data for A. hypogaea L. was normalized using the geometric mean (geomean) of the validated

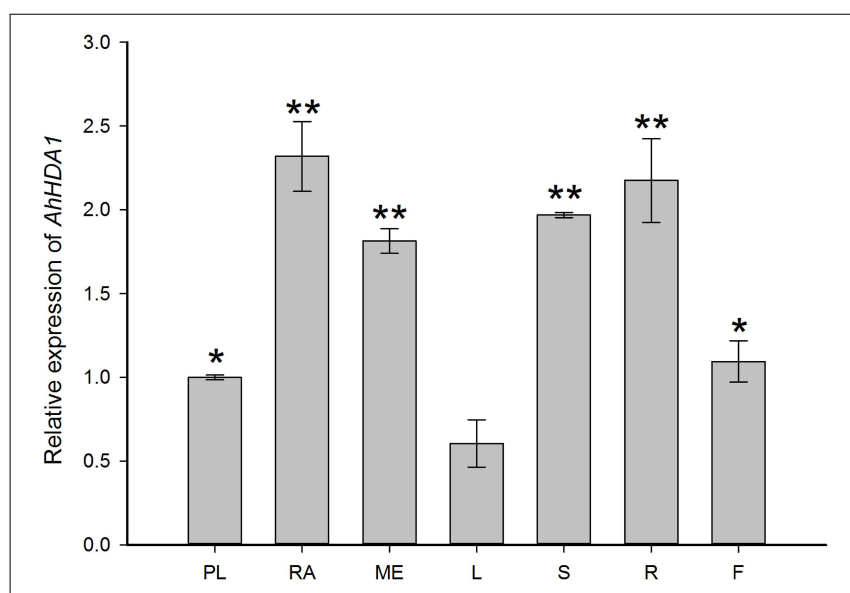

FIGURE 3 | Quantitative RT-PCR validations of AhHDA1 expression in different peanut tissues. Column chart showing expression of $A h H D A 1$ in PL, plumule; RA, radicle; ME, mesocotyl; L, leaf; S, stem; R, root; and F, flower, respectively. Plumules, radicles, and mesocotyls were taken from peanut embroys which had been cultivated for 7 days germination. Leaves stems and roots were taken from four-leaf stage peanut seedlings. Flowers were taken from peanuts during budding. All plants were grown as started in Materials and Methods. All values \pm Standard Error (SE) for $n=3$ biological replicates. Each graph displays the mean and SD of three independent experiments. ${ }^{* / *}$, different from control as revealed by $t$-test, $p<0.05 / p<0.01$. housekeeping genes, ACTIN and ADH3 (Chi et al., 2012; Reddy et al., 2013): the primers ACT11-F and ACT11-R, specific to the peanut ACTIN gene (GenBank accession no. GO339334), were used to amplify a fragment of $108 \mathrm{bp}$, and the primers $A D H 3$ $\mathrm{F}$ and $A D H 3-\mathrm{R}$, specific to the peanut $A D H 3$ gene (GenBank accession no. EG529529), were used to amplify a fragment of 143 bp. The mean values shown $( \pm S E)$ were calculated from three biological replicates. Primers are listed in Table S1.

\section{Production of Recombinant AhHDA1 in E. Coli}

The PCR product of AhHDA1 was cloned into an E. coli expression vector, pPROEX HT (Invitrogen, catalog No. 10711018) (Pompon et al., 1996). The resulting plasmid was transformed into E. coli strain BL21 (Figure S2). Transformants were grown in LB medium ( $10 \mathrm{~g} / \mathrm{L}$ Tryptone, $5 \mathrm{~g} / \mathrm{L}$ yeast extract, $10 \mathrm{~g} / \mathrm{L}$ sodium chloride, $50 \mathrm{~g} / \mathrm{mL}$ ampicillin) at $37^{\circ} \mathrm{C}$ for $8-$ $10 \mathrm{~h}$. Once the OD600 reached 0.7, $0.1 \mathrm{mM}$ IPTG was added to the LB medium. Then the bacterial suspension was placed in a shaking incubator at $16^{\circ} \mathrm{C}$ for $20 \mathrm{~h}$. To prepare total proteins, E. coli cells were collected and suspended in $0.1 \mathrm{~mol} / \mathrm{L}$ potassium phosphate buffer ( $\mathrm{pH}$ 7.6). The lysates of the bacterial cells were centrifuged (at $4^{\circ} \mathrm{C}, 10,000 \mathrm{rpm}, 10 \mathrm{~min}$ ), and the supernatants were subjected to Ni-NTA HisTrap FF crude column chromatography for purification of the recombinant protein. The purified protein was dissolved in phosphatebuffered saline ( $\mathrm{pH} 7.6)$ to a final concentration of $0.8 \mathrm{mg} / \mathrm{mL}$. The purity of the recombinant AhHDAl protein was analyzed using SDS-PAGE.

\section{HDAC Enzyme Activity Assay (Colorimetric Detection)}

This two-step procedure was performed in a microtiter plate using an HDAC Assay Kit (Millipore, catalog no. 17-374). Each well-contained $10 \mu \mathrm{l} 2 \mathrm{X}$ HDAC assay buffer, or $2 \mathrm{X}$ HDAC assay buffer containing $4 \mu \mathrm{M}$ trichostatin A, to which $20 \mu \mathrm{l}$ test protein sample, or $20 \mu \mathrm{l} \mathrm{HeLa}$ nuclear extract (positive control; supplied with kit) or $20 \mu$ l water (negative control) were added; the plate was then equilibrated at the assay temperature $\left(37^{\circ} \mathrm{C}\right)$. After adding $10 \mu \mathrm{l}$ of the $4 \mathrm{mM}$ HDAC assay substrate and mixing thoroughly, the microtiter plate was incubated at $37^{\circ} \mathrm{C}$ for $60 \mathrm{~min}$. Then $20 \mu \mathrm{l}$ of the diluted activator solution was added to each well, mixed thoroughly and the microtiter plate was incubated at room temperature for $15 \mathrm{~min}$. The absorbance was read in a plate reader at $405 \mathrm{~nm}$.

\section{Results}

\section{PEG and ABA Mediate Alterations of H3K9 and H3K14 Acetylation Status in Arachis hypogaea L. Leaves}

The histone acetylation status of chromatin was investigated in peanut leaves subjected to PEG-induced osmotic stress or to treatment with the stress-protective hormone $\mathrm{ABA}$. Immunoblotting experiments showed that the $\mathrm{H} 3 \mathrm{~K} 9 \mathrm{ac}$ level increased with 20\% PEG treatment, while the H3K14ac level increased with $100 \mu \mathrm{M} \mathrm{ABA}$ treatment (Figure 1). H3K9ac 
levels following PEG treatment began to increase from $2 \mathrm{~h}$ and continued to increase through to the $8 \mathrm{~h}$ time point; thus, after $5 \mathrm{~h} \mathrm{H} 3 \mathrm{~K} 9 \mathrm{ac}$ levels showed a significant increase to 7 times that of the control group, and at $8 \mathrm{~h}$ had increased further to 23 times control levels. Treatment with PEG produced only a marginal increase in $\mathrm{H} 3 \mathrm{~K} 14 \mathrm{ac}$ levels at $8 \mathrm{~h}$, but ABA treatment significantly increased the amount of $\mathrm{H} 3 \mathrm{~K} 14 \mathrm{ac}$ by $5 \mathrm{~h}$ to 8 times that of the control group. The results indicate that both PEG and ABA can mediate changes in acetylation at different histone $\mathrm{H} 3$ loci; these different patterns of modification suggest that the two treatments result in different gene activation profiles in peanut leaves. At the same time, it has also been proved that the acetylation of $\mathrm{H} 3 \mathrm{~K} 9$, $\mathrm{H} 3 \mathrm{~K} 14$, and $\mathrm{H} 3$ were increased with $1 \mu \mathrm{M}$ TSA treatment from 1 to $8 \mathrm{~h}$ (Figure $\mathrm{S} 4$ ).

\section{Isolation and Characterization of the Peanut AhHDA1 Gene}

From the above results, it is clear that osmotic stress and ABA affect the acetylation of histone $\mathrm{H} 3$. We therefore screened an RNA-seq database which identifies genes that are differentially expressed following PEG and ABA treatment of peanut (http://www.ncbi.nlm.nih.gov/bioproject/243319) and found a full length ORF of a sequence (comp66763_c0) similar to the Arabidopsis HDA6 gene. According to the RNA-seq data, this gene, named AhHDA1 (GenBank accession No. KC690279), is inducible by PEG and ABA treatment in peanut leaves from four-leaf seedlings.

Specific forward and reverse primers (ORF1-F and ORF1R) were designed from comp66763_c0 to isolate an AhHDA1 cDNA as detailed in Materials and Methods. By sequence alignment, the predicted sequence of the AhHDA1 protein showed a high degree of similarity with other HDACs in the GenBank DNA database, and AhHDA1 possessed the same active site and $\mathrm{Zn}^{2+}$ binding sites as other plant HDACs (Figure 2A). AhHDA1 consists of a polypeptide of 467 amino acid residues with a calculated molecular weight of $52.37 \mathrm{kDa}$ and an isoelectric point of 5.28. It can be deduced from Figure $2 \mathbf{B}$ that AhHDA1 is most similar to counterparts in eudicots, especially soybean.

The SWISS-MODEL tool was used to generate 3D structures for the AtHDA6 (encoded by the Arabidopsis HDA6 gene) and AhHDA1 proteins (http://www.swissmodel.expasy. org; Figure S1). The 3D structures of both AhHDA1 and AtHDA6 were very similar, implying that the AhHDA1 gene in peanut has a similar function to that of AtHDA6 in Arabidopsis.

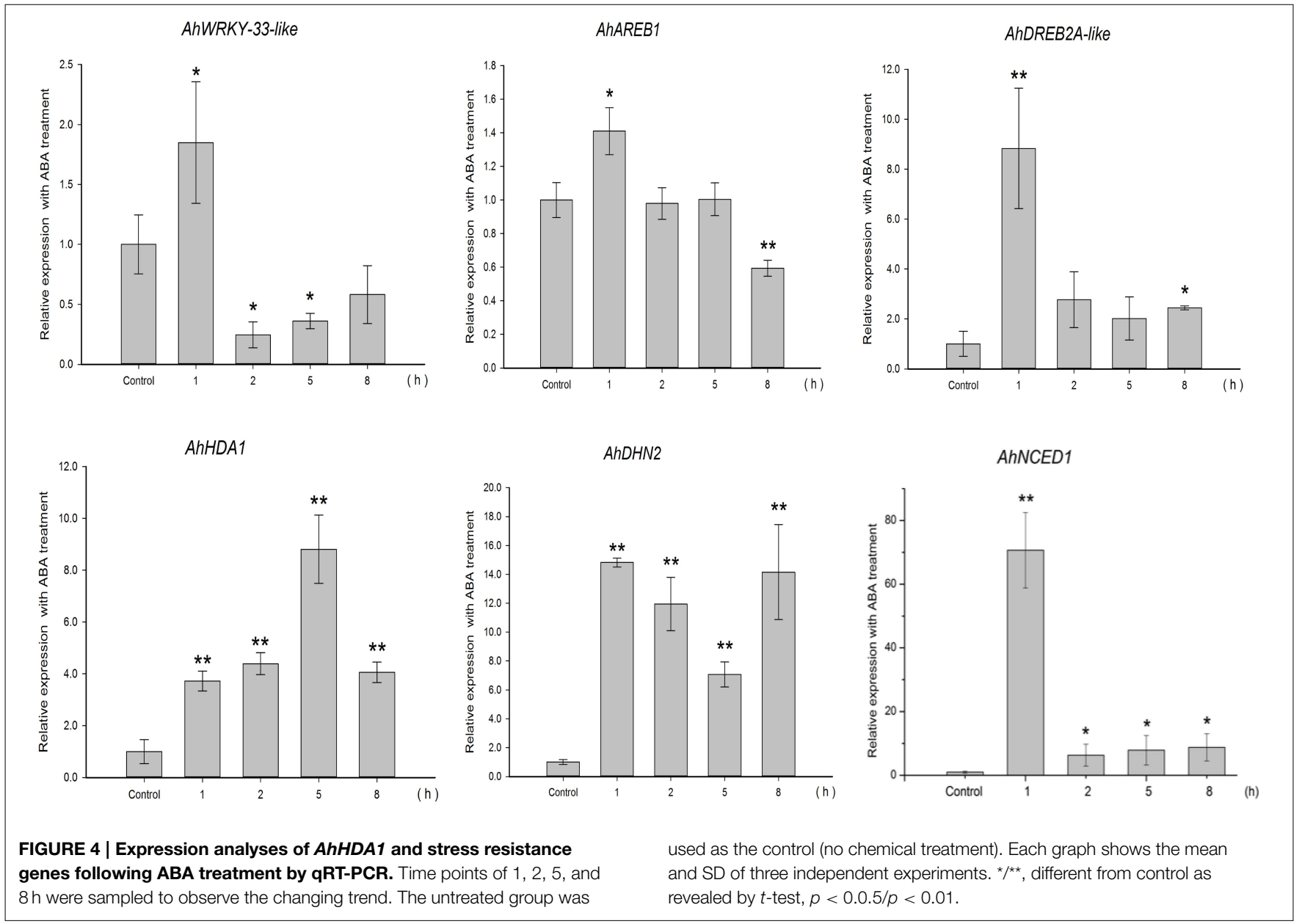




\section{Differential Expression Analysis in Different Tissues of Arachis Hypogaea L.}

Quantitative RT-PCR analysis was performed to examine the expression of AhHDA1 in untreated embryos (plumule, radicle, and mesocotyl) and four-leaf seedlings (leaf, stem, root, and flower) (Figure 3). AhHDA1 mRNA predominantly accumulates in radicle and mesocotyl of the embryo; similarly, in seedlings, AhHDA1 mRNA predominantly accumulates in stem and root.

\section{Enhancement of AhHDA1 Transcript Level in Peanut Leaves from Four-leaf Seedlings in Response to Osmotic Stress, ABA, and Histone Deacetylase Inhibitor}

To gain insight into the regulation of AhHDA1, qRT-PCR analyses were carried out in peanut leaves from four-leaf seedlings using gene-specific internal primers (Table 1). We investigated the changing trend of AhHDA1 expression resulting from $\mathrm{ABA}$ treatment, as well as during the first rapid phase of water stress resulting from treatment with PEG. At the same time, the specific HDAC inhibitor TSA was used to examine the role of AhHDA1 in the response to ABA and osmotic stress (Figure S4). Drought resistance genes were also analyzed with all these treatments. By comparison with the control group, we found that the expression of $A h H D A 1$ was enhanced by all three treatments (Figures 4-6). The AhHDA1 transcript level increased to 4 times that of the control group at $1 \mathrm{~h}$, and remained at a relatively high level from 2 to $8 \mathrm{~h}$ in ABA-treated plants. PEG and TSA treatments gave an expression profile almost identical to that of ABA-treated seedlings: AhHDA1 expression in TSA groups increased from $1 \mathrm{~h}$ and stayed at a high level throughout the remainder of the experiment, while AhHDA1 expression in PEG groups increased from $5 \mathrm{~h}$, rather than $1 \mathrm{~h}$, and stayed high at $8 \mathrm{~h}$

The expression profiles of TF genes (AhAREB1, AhDREB2Alike, $A h W R K Y 33$-like) and functional genes ( $A h D H N 2$ and $A h N C E D 1)$ were also determined in all three groups. It is clear from our results (Figures 4-6) that the expression patterns of these TF genes and functional genes in peanut leaves were very similar to that of AhHDA1, both of which show an initial increase followed by a decline in expression. More specifically, the expression of AhAREB1, AhDREB2A-like, and AhWRKY33like began to increase at $1 \mathrm{~h}$ in both $A B A$ and TSA groups and stayed at a high level or decreased from $2 \mathrm{~h}$. AhAREB1 and $A h W R K Y 33$-like expression began to increase from $5 \mathrm{~h}$ during PEG treatment, while the expression of AhDREB2A-like increased from $2 \mathrm{~h}$. At the same time, the expression of $A h D H N 2$ and $A h N C E D 1$, the functional genes, began to increase from $1 \mathrm{~h}$ in all three treatment groups and maintained a high level of expression after $2 \mathrm{~h}$.

\section{Histone Deacetylase Activity of Recombinant AhHDA1 Protein}

Recombinant AhHDA1 was produced in E. coli (Figure S2) as a polypeptide of about $53 \mathrm{kDa}$ (Figure 7A). A total protein

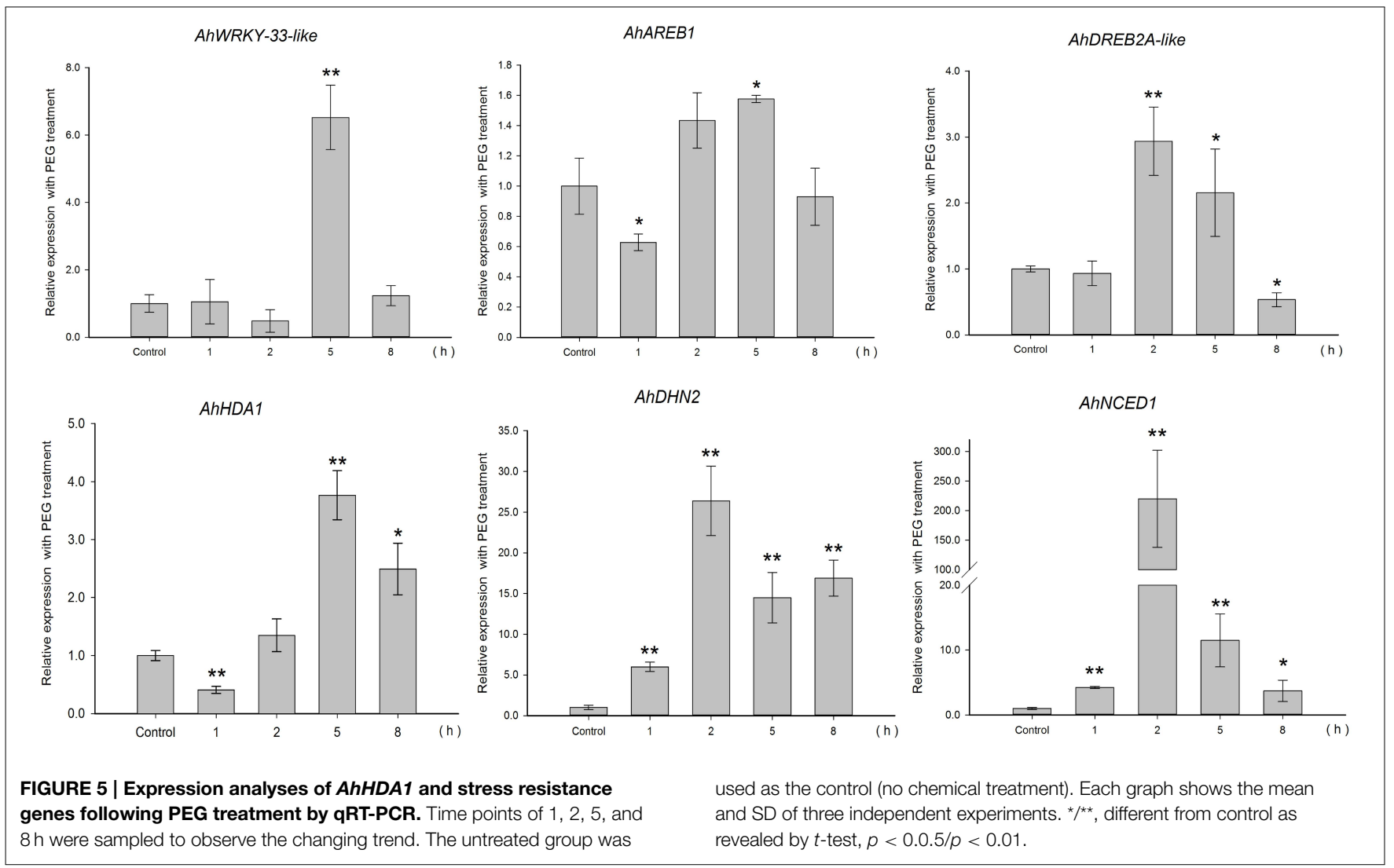




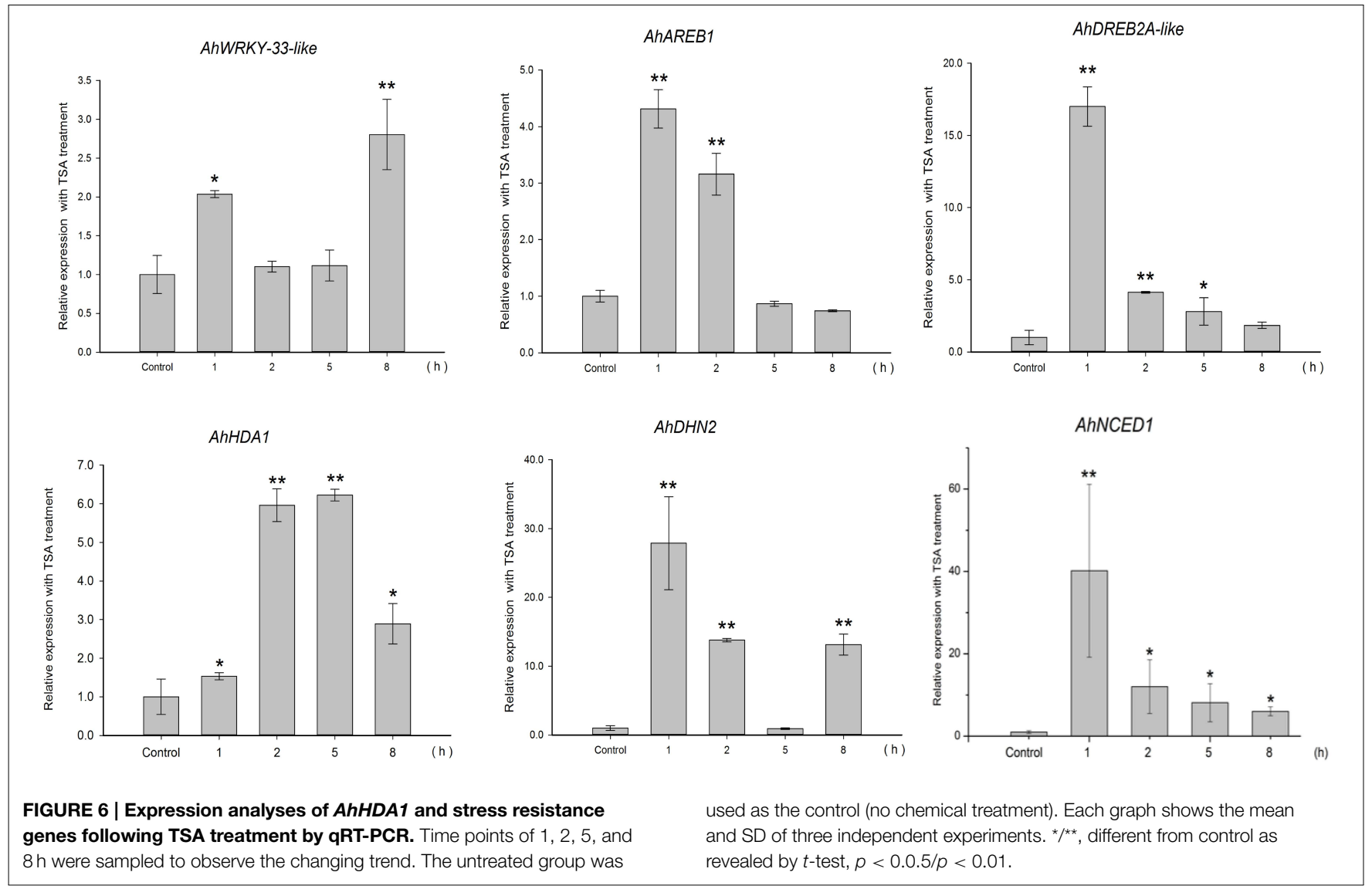

extract from E. coli expressing AhHDA1 was tested for HDAC activity (Figure 7B, Figure S3). The HDAC activity of an extract from cells containing plasmid pPROEX (i.e., the expression vector control) and the HDAC activity of an extract from cells containing plasmid pPROEX-AhHDA1 without IPTG treatment were 4.6 and $5.2 \mathrm{U} / \mathrm{mg}$, respectively. When AhHDA1 expression was induced by IPTG treatment, HDAC activity of the cell extract increased to $54.1 \mathrm{U} / \mathrm{mg}$; purified recombinant AhHDA1 protein gave an activity of $21.0 \mathrm{U} / \mathrm{mg}$. When the HDAC inhibitor TSA was added to either the induced cell extract or to purified recombinant AhHDA1 protein, the HDAC activity decreased to 17.0 and $7.4 \mathrm{U} / \mathrm{mg}$, respectively. The presence of HDAC activity correlated with expression of recombinant AhHDA1 protein after induction by IPTG, suggesting that the peanut protein is functional; the results also confirm that TSA effectively inhibits AhHDA1 activity.

\section{Discussion}

\section{The Consequences of Osmotic Stress and ABA Treatment for Histone Acetylation of H3K9 and H3K14 and Gene Expression in Arachis Hypogaea L.}

Histone acetylation is a common modification of plant chromatin and plays a critical role in the epigenetic control of gene expression. It is involved in the response to both drought and $\mathrm{ABA}$ in various plants, including Arabidopsis, rice, and maize (Hu et al., 2011; Vlachonasios et al., 2011; Fang et al., 2014). $\mathrm{Kim}$ et al. have proposed that enrichment of $\mathrm{H} 3 \mathrm{~K} 9 \mathrm{ac}$, but not $\mathrm{H} 3 \mathrm{~K} 14 \mathrm{ac}$, correlates with gene activation in the coding regions of drought-responsive genes in Arabidopsis (Kim et al., 2008). However, in peanut, we found that water limitation resulted in increased acetylation of both $\mathrm{H} 3 \mathrm{~K} 9$ and $\mathrm{H} 3 \mathrm{~K} 14$, albeit at different time points. Thus, H3K9ac levels were significantly enhanced by $2 \mathrm{~h}$ of PEG treatment, and continued to increase throughout the experiment (up to $8 \mathrm{~h}$ ). In contrast, H3K14ac levels increased, but not until $8 \mathrm{~h}$ after osmotic stress was imposed (Figure 1A). A different result was obtained with ABA: increased acetylation of H3K14 was observed after treatment for $5 \mathrm{~h}$ (Figure 1B), but there was relatively little effect on H3K9 acetylation for the duration of the experiment. Thus, the degree of acetylation in each case indicates that osmotic stress stimulates histone acetylation mainly at the $\mathrm{H} 3 \mathrm{~K} 9$ locus, whereas ABA induces histone acetylation primarily on $\mathrm{H} 3 \mathrm{~K} 14$. An explanation for this result might be that stress-responsive gene expression is governed by two different types of TF, AREB/ABFs, and DREB2A, which operate through the ABA-dependent and ABAindependent signaling pathways, respectively (Sreenivasulu et al., 2006; Fujita et al., 2011; Yoshida et al., 2014). Thus, the SnRK2AREB (ABA-responsive element binding)/ABF pathway governs the majority of ABA-mediated AREB-dependent gene expression 


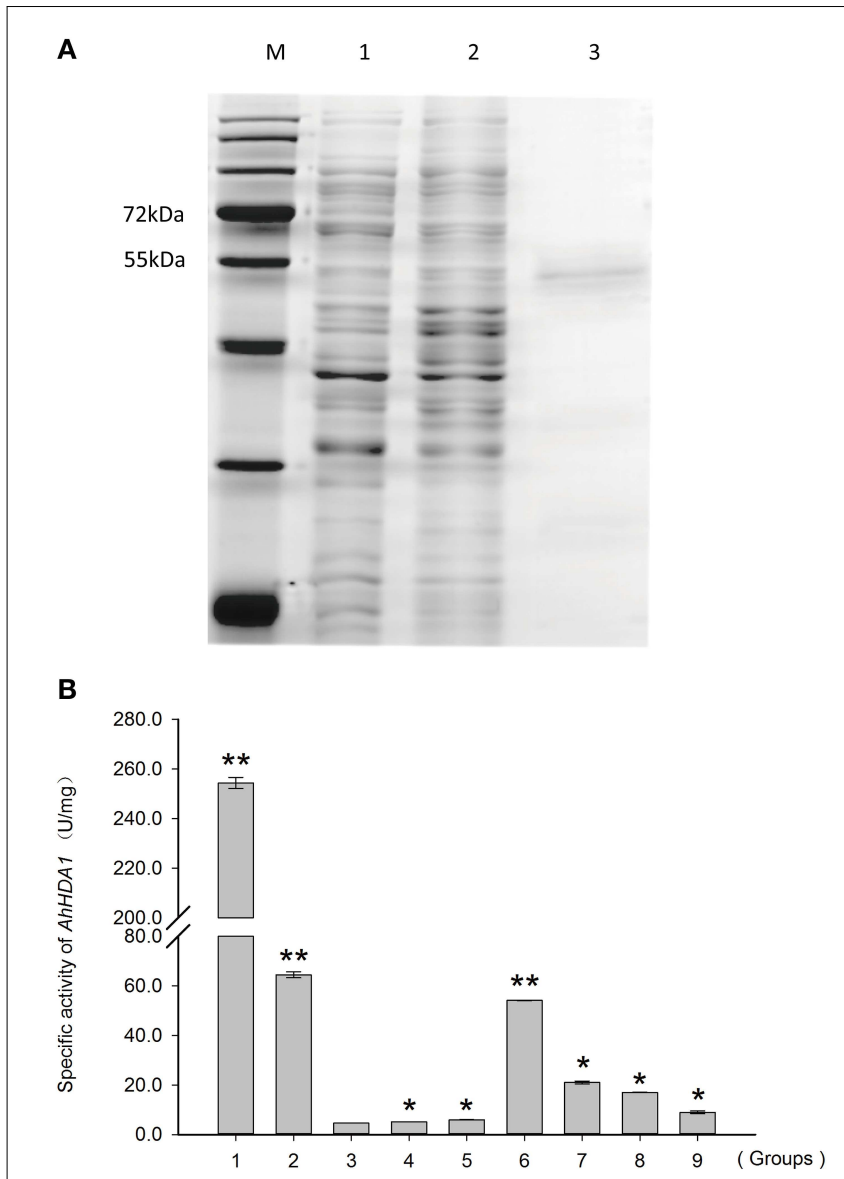

FIGURE 7 | HDAC activity of recombinant AhHDA1 produced in E. coli BL21. (A) SDS-PAGE showing (1) total protein from $E$. coli cells expressing the recombinant plasmid pPROEX-AhHDA1 before induction by IPTG; (2) total protein from $E$. coli cells expressing recombinant plasmid pPROEX-AhHDA1 after induction by IPTG; for $20 \mathrm{~h}$; and (3) purified AhHDA1 protein. (B) In vitro HDAC activity assay of the recombinant AhHDA1 protein. 1, positive control, extract from Hela cells; 2, extract from Hela cells treated with $4 \mu \mathrm{M}$ TSA; 3 , negative control, extract form E. coli cells containing plasmid pPROEX; 4, extract from $E$. coli cells containing plasmid pPROEX-AhHDA1 without IPTG; 5, extract from cells containing plasmid pPROEX after induction by IPTG; 6 , extract from cells containing plasmid pPROEX-AhHDA1 after induction by IPTG for $20 \mathrm{~h}$; 7 , extract from cells containing plasmid pPROEX-AhHDA1 after induction by IPTG, but treated with $4 \mu \mathrm{M}$ TSA for $20 \mathrm{~h}$; 8 , purified recombinant AhHDA1 protein; 9, purified recombinant AhHDA1 protein treated with $4 \mu \mathrm{M}$ TSA. Each graph shows the mean and SD of three independent experiments. ${ }^{\star * *}$, different from control as revealed by $t$-test, $p<0.0 .5 / p<0.01$.

in response to osmotic stress during the vegetative stage of Arabidopsis (Fujita et al., 2011), while an ABA-independent but interactive pathway acts via the dehydration-responsive element binding (DREB) 2A TF (Sreenivasulu et al., 2006).

The effect of osmotic stress and exogenous ABA function on AhHDA1 was examined and it was found to be up-regulated by both PEG and ABA early in the response to both treatments (Figures 4, 5). However, the mechanisms underlying these responses are not known, and therefore it is not clear whether ABA and osmotic stress act on $A h H D A 1$ via a common pathway or via independent pathways. Given that AhHDA1 transcription begins to increase significantly after $1 \mathrm{~h}$ of ABA treatment, but not until $2 \mathrm{~h}$ after PEG treatment, and that H3K14ac increases from $1 \mathrm{~h}$ of $\mathrm{ABA}$ treatment, while $\mathrm{H} 3 \mathrm{~K} 9 \mathrm{ac}$ increases from $2 \mathrm{~h}$ of PEG treatment, it is possible that ABA-dependent stressresponsive genes are activated through modification of the H3K14 locus, and ABA-independent stress-responsive genes are activated at the $\mathrm{H} 3 \mathrm{~K} 9$ locus. The increased AhHDA1 expression induced by PEG or ABA might result from rapid changes in the HDAC and HAT "switches," which re-balance histone and deacetylation.

\section{AhHDA1 is a RPD3/HDA1 Histone Deacetylase Subfamily Protein and is Structurally Similar to AtHDA6}

Based on our understanding of the relationship between stress and histone acetylation, together with our analysis of RNAseq data, we may surmise that HDAC activity in peanut plays an important role in the responses to both osmotic stress and ABA treatment. In this paper, we isolated and characterized AhHDA1 from A. hypogaea L. cv Yueyou 7, a drought-resistant peanut variety we have reported on in previous studies (Fang et al., 2007). AhHDA1 accumulates in the stem and root in seedlings, while it predominantly accumulates in the radicle and mesocotyl in the embryo (Figure 3). Both the predicted sequence and structure of the AhHDA1 protein appear to be well-conserved as judged by multiple sequence alignment, phylogenetic analysis and comparison of AtHDA6 and AhHDA1 ribbon diagrams (Figure 2, Figure S1). The HDAC activity of AhHDA1 was demonstrated by heterologous expression of recombinant protein in bacteria and this activity was inhibited by the specific HDAC inhibitor TSA. Using the Arabidopsis HDA6 mutant axe1-5 and HDA6 RNA-interfering plants, which display higher sensitivity to $\mathrm{NaCl}$ and $\mathrm{ABA}$ than wild type, Chen et al. found AtHDA6 to be involved in histone modifications that modulate seed germination and the salt stress response (Chen et al., 2010). AtHDA6 mutations also result in transcriptional gene silencing, which influences the expression of auxininducible genes (Murfett et al., 2001). Given its structural relatedness to AtHDA6, AhHDA1 may possess similar functions.

\section{The Relationship between Environmental Stress, Histone Acetylation Status and Activity of Stress Resistance Genes}

TSA is an HDAC inhibitor that induces transient hyperacetylation of histones $\mathrm{H} 2 \mathrm{~B}, \mathrm{H} 4$, and $\mathrm{H} 3$ (Waterborg, 2011). Drought-induced $R A B 18, R D 29 B, H S P 70$ and four late embryogenesis abundant protein genes ( $L E A)$ are up-regulated by TSA in imbibing $A$. thaliana seeds (Tai et al., 2005). In our studies, TSA promoted the expression of AhHDA1 (Figure 6) and induced acetylation of $\mathrm{H} 3$ (Figure $\mathrm{S} 4$ ). The expression patterns of three TF genes (AhAREB1, AhDREB2A-like, and $A h W R K Y 33-$ like) and two functional genes (AhDHN2 and $A h N C E D 1)$ were also determined to study how TSA acted on stress resistance genes. TF gene expression was found to increase at an early time point after TSA treatment, then decreased as time went on. Although the expression profile of the functional 
genes was similar, the transcript level of these genes remained high relative to the control groups.

Because HDACs are inhibited by TSA which induces transient hyperacetylation of histone H3 (Figure 7, Figure S4) (Finnin et al., 1999), it seems reasonable to suppose that the up-regulated expression of AhHDA1 following TSA treatment results from a feedback mechanism to re-establish the balance of histone acetylation and diacetylation in the plant. We might speculate that the mechanism of action of environmental stress, including osmotic stress and ABA signaling, on AhHDA1 expression is as follows: histone acetylation is enhanced in peanut leaves soon after they are exposed to osmotic stress or ABA; subsequently, upstream TFs become activated and induce the expression of functional genes. Later, TF activity is modulated to a relatively insensitive state as the products of functional genes, such as the dehydrin AhDHN2, begin to protect plant cells from environmental stress damage.

Our work on AhHDA1 has encompassed bioinformatic analysis of the gene, in vitro activity analysis of the corresponding recombinant protein and analysis of the effects of osmotic stress and ABA on AhHDA1 expression. We conclude that AhHDA1, which is very similar to AtHDA6, is up-regulated by osmotic stress, ABA, and TSA. Future studies will focus on which genes undergo specific histone acetylation in response to water

\section{References}

Arnold, K., Bordoli, L., Kopp, J., and Schwede, T. (2006). The SWISSMODEL workspace: a web-based environment for protein structure homology modelling. Bioinformatics 22, 195-201. doi: 10.1093/bioinformatics/bti770

Chen, L. T., Luo, M., Wang, Y. Y., and Wu, K. (2010). Involvement of Arabidopsis histone deacetylase HDA6 in ABA and salt stress response. J. Exp. Bot. 61, 3345-3353. doi: 10.1093/jxb/erq154

Chi, X. Y., Hu, R., Yang, Q., Zhang, X., Pan, L., Chen, N., et al. (2012). Validation of reference genes for gene expression studies in peanut by quantitative real-time RT-PCR. Mol. Genet. Genomics 287, 167-176. doi: 10.1007/s00438-011-0665-5

Cigliano, R. A., Cremona, G., Paparo, R., Termolino, P., Perrella, G., and Gutzat, R. (2013). Histone deacetylase AtHDA7 is required for female gametophyte and embryo development in Arabidopsis. Plant Physiol. 163, 431-440. doi: $10.1104 /$ pp.113.221713

Devoto, A., Nieto-Rostro, M., Xie, D., Ellis, C., Harmston, R., Patrick, E., et al. (2002). COI1 links jasmonate signalling and fertility to the SCF ubiquitinligase complex in Arabidopsis. Plant J. 32, 457-466. doi: 10.1046/j.1365313X.2002.01432.x

Fang, H., Liu, X., Thorn, G., Duan, J., and Tian, L. (2014). Expression analysis of histone acetyltransferases in rice under drought stress. Biochem. Biophys. Res. Commun. 443, 400-405. doi: 10.1016/j.bbrc.2013.11.102

Fang, X. L., Liao, W. Q., Xiao, L. C., Zhou, G. Y., Li, D. Y., and Cai, S. H. (2007). A primary report on the introduction and demonstration of super high yield peanut variety Yueyou7. J. Peanut Sci. 36, 38-40. doi: 10.3969/j.issn.10024093.2007.02.009

Finnin, M. S., Donigian, J. R., Cohen, A., Richon, V. M., Rifkind, R. A., Marks, P. A., et al. (1999). Structures of a histone deacetylase homologue bound to the TSA and SAHA inhibitors. Nature 401, 188-193. doi: 10.1038/43710

Fong, P. M., Tian, L., and Chen, Z. J. (2006). Arabidopsis thaliana histone deacetylase 1 (AtHD1) is localized in euchromatic regions and demonstrates histone deacetylase activity in vitro. Cell Res. 16, 479-488. doi: 10.1038/sj.cr.7310059

Fujita, Y., Fujita, M., Shinozaki, K., and Yamaguchi-Shinozaki, K. (2011). ABAmediated transcriptional regulation in response to osmotic stress in plants. J. Plant Res. 124, 509-525. doi: 10.1007/s10265-011-0412-3 limitation and $\mathrm{ABA}$ treatment, and on an investigation of the critical genes in ABA-dependent and ABA-independent signaling pathways. These might help elucidate the molecular mechanisms of drought resistance, results that could be used to produce new varieties of crops for cultivation in water-limiting conditions.

\section{Author Contributions}

LCS, drafted the manuscript; $\mathrm{BD}$, conducted the bioinformatics analysis; LL, LCS, BD, conceived and designed the experiments; LCS, BD, SL, LML, BH, YTZ, performed the experiments; $\mathrm{BH}$, analyzed the data; LL, contributed reagents/materials/analysis tools.

\section{Funding}

This work was supported by grants from the National Natural Science Foundation of China (No. 31471422 granted to LL).

\section{Supplementary Material}

The Supplementary Material for this article can be found online at: http://journal.frontiersin.org/article/10.3389/fpls.2015. 00512
Henderson, I. R., and Jacobsen, S. E. (2007). Epigenetic inheritance in plants. Nature 447, 418-424. doi: 10.1038/nature05917

Hu, Y., Zhang, L., Zhao, L., Li, J., He, S., and Zhou, K. (2011). Trichostatin A selectively suppresses the cold-induced transcription of the ZmDREB1 gene in maize. PLoS ONE 6:e22132. doi: 10.1371/journal.pone.0022132

Jung, Y. C., Lee, H. J., Yum, S. S., Soh, W. Y., Cho, D. Y., Auh, C. K., et al. (2005) Drought-inducible-but ABA-independent- thaumatin-like protein from carrot (Daucus carota L.). Plant Cell Rep. 24, 366-373. doi: 10.1007/s00299-0050944-x

Kim, J. M., To, T. K., Ishida, J., Morosawa, T., Kawashima, M., Matsui, A., et al. (2008). Alterations of lysine modifications on the histone H3 N-tail under drought stress conditions in Arabidopsis thaliana. Plant Cell Physiol. 49, 1580-1588. doi: 10.1093/pcp/pcn133

Kim, J. M., To, T. K., Nishioka, T., and Seki, M. (2010). Chromatin regulation functions in plant abiotic stress responses. Plant Cell Environ. 33, 604-611. doi: 10.1111/j.1365-3040.2009.02076.x

Kurdistani, S. K., and Grunstein, M. (2003). Histone acetylation and deacetylation in yeast. Nat. Rev. Mol. Cell Biol. 4, 276-284. doi: 10.1038/nrm1075

Li, X., Lu, J., Liu, S., Liu, X., Lin, Y., and Li, L. (2014). Identification of rapidly induced genes in the response of peanut (Arachis hypogaea) to water deficit and abscisic acid. BMC Biotechnol. 14:58. doi: 10.1186/1472-6750-14-58

Li, X. Y., Liu, X., Yao, Y., Li, Y. H., Liu, S., and He, C. Y., et al. (2013). Overexpression of Arachis hypogaea AREB1 gene enhances drought tolerance by modulating ROS scavenging and maintaining endogenous ABA content. Int. J. Mol. Sci. 14, 12827-12842. doi: 10.3390/ijms140612827

Liu, C., Li, L. C., Chen, W. Q., Chen, X., Xu, Z. H., and Bai, S. N. (2013). HDA18 affects cell fate in Arabidopsis root epidermis via histone acetylation at four kinase genes. Plant Cell 25, 257-269. doi: 10.1105/tpc.112. 107045

Liu, Q., Kasuga, M., Sakuma, Y., Abe, H., Miura, S., Yamaguchi-Shinozaki, K., et al. (1998). Two transcription factors, DREB1 and DREB2, with an EREBP/AP2 DNA binding domain separate two cellular signal transduction pathways in drought- and low-temperature-responsive gene expression, respectively, in Arabidopsis. Plant Cell 10, 1391-1406. doi: 10.1105/tpc.10.8.1391

Loidl, P. (2004). A plant dialect of the histone language. Trends Plant Sci. 9, 84-90. doi: 10.1016/j.tplants.2003.12.007 
Lopez-Gonzalez, L., Mouriz, A., Narro-Diego, L., Bustos, R., Martínez-Zapater, J. M., Jarillo, J. A., et al. (2014). Chromatin-dependent repression of the arabidopsis floral integrator genes involves plant specific PHD-containing proteins. Plant Cell. 26, 3922-3938. doi: 10.1105/tpc.114.130781

Ma, X., Lv, S., Zhang, C., and Yang, C. (2013). Histone deacetylases and their functions in plants. Plant Cell Rep. 32, 465-478. doi: 10.1007/s00299-0131393-6

Muller, P. Y., Janovjak, H., Miserez, A. R., and Dobbie, Z. (2002). Processing of gene expression data generated by quantitative real-time RT-PCR. Biotechniques 32, 1372-1379. doi: 10.1093/bioinformatics/btg157

Murfett, J., Wang, X. J., Hagen, G., and Guilfoyle, T. J. (2001). Identification of arabidopsis histone deacetylase HDA6 mutants that affect transgene expression. Plant Cell 13, 1047-1061. doi: 10.1105/tpc.13.5.1047

Pandey, R., Müller, A., Napoli, C. A., Selinger, D. A., Pikaard, C. S., Richards, E. J., et al. (2002). Analysis of histone acetyltransferase and histone deacetylase families of Arabidopsis thaliana suggests functional diversification of chromatin modification among multicellular eukaryotes. Nucleic Acids Res. 30, 5036-5055. doi: 10.1093/nar/gkf660

Pompon, D., Louerat, B., Bronine, A., and Urban, P. (1996). Yeast expression of animal and plant P450s in optimized redox environments. Meth. Enzymol. 272, 51-64. doi: 10.1016/S0076-6879(96)72008-6

Reddy, D. S., Bhatnagar-Mathur, P., Cindhuri, K. S., and Sharma, K. K. (2013). Evaluation and validation of reference genes for normalization of quantitative real-time PCR based gene expression studies in peanut. PLoS ONE 8:e78555. doi: 10.1371/journal.pone.0078555

Roy, D., Paul, A., Roy, A., Ghosh, R., Ganguly, P., and Chaudhuri, S. (2014). Differential acetylation of histone $\mathrm{H} 3$ at the regulatory region of OsDREB1b promoter facilitates chromatin remodelling and transcription activation during cold stress. PLoS ONE 9:e100343. doi: 10.1371/journal.pone.0100343

Schwede, T., Kopp, J., Guex, N., and Peitsch, M. C. (2003). SWISS-MODEL: an automated protein homology-modeling server. Nucleic Acids Res. 31, 3381-3385. doi: 10.1093/nar/gkg520

Sreenivasulu, N., Radchuk, V., Strickert, M., Miersch, O., Weschke, W., and Wobus, U. (2006). Gene expression patterns reveal tissue-specific signaling networks controlling programmed cell death and ABA- regulated maturation in developing barley seeds. Plant J. 47, 310-327. doi: 10.1111/j.1365313X.2006.02789.x

Su, L. C., Liu, X., Chen, Y. P., and Li, L. (2012). Isolation of AhDHNs from Arachis hypogaea L. and evaluation of AhDHNs expression under exogenous abscisic acid (ABA) and water stress. Afr. J. Biotechnol. 11, 11221-11229. doi: 10.5897/AJB11.3844

Tai, H. H., Tai, G. C., and Beardmore, T. (2005). Dynamic histone acetylation of late embryonic genes during seed germination. Plant Mol. Biol. 59, 909-925. doi: 10.1007/s11103-005-2081-x

Tanaka, M., Kikuchi, A., and Kamada, H. (2008). The Arabidopsis histone deacetylases HDA6 and HDA19 contribute to the repression of embryonic properties after germination. Plant Physiol. 146, 149-161. doi: 10.1104/pp.107.111674

van Zanten, M., Zöll, C., Wang, Z., Philipp, C., Carles, A., Li, Y., et al. (2014). HISTONE DEACETYLASE 9 represses seedling traits in Arabidopsis thaliana dry seeds. Plant J. 80, 475-488. doi: 10.1111/tpj.12646
Vlachonasios, K. E., Kaldis, A., Nikoloudi, A., and Tsementzi, D. (2011). The role of transcriptional coactivator ADA2b in Arabidopsis abiotic stress responses. Plant Signal. Behav. 6, 1475-1478. doi: 10.4161/psb.6. 10.17695

Wan, X., and, Li, L. (2005). Molecular cloning and characterization of a dehydration-inducible cDNA encoding a putative 9-cis-epoxycarotenoid dioxygenase in Arachis hygogaea L. DNA Seq. 16, 217-223. doi: 10.1080/10425170500129785

Wan, X., Mo, A., Liu, S., Yang, L., and Li, L. (2011). Constitutive expression of a peanut ubiquitin-conjugating enzyme gene in Arabidopsis confers improved water-stress tolerance through regulation of stress-responsive gene expression. J. Biosci. Bioeng. 111, 478-484. doi: 10.1016/j.jbiosc.2010.11.021

Wan, X. R., and Li, L. (2006). Regulation of ABA level and water-stress tolerance of Arabidopsis by ectopic expression of a peanut 9-cis-epoxycarotenoid dioxygenase gene. Biochem. Biophys. Res. Commun. 347, 1030-1038. doi: 10.1016/j.bbrc.2006.07.026

Waterborg, J. H. (2011). Plant histone acetylation: in the beginning. Biochim. Biophys. Acta 1809, 353-359. doi: 10.1016/j.bbagrm.2011.02.005

Yoshida, T., Mogami, J., and Yamaguchi-Shinozaki, K. (2014). ABA-dependent and ABA-independent signaling in response to osmotic stress in plants. Curr. Opin. Plant Biol. 21, 133-139. doi: 10.1016/j.pbi.2014.07.009

Zhang, Q., Lei, X., and Lu, H. (2014). Alterations of epigenetic signatures in hepatocyte nuclear factor 4alpha deficient mouse liver determined by improved ChIP-qPCR and (h) MeDIP-qPCR assays. PLoS ONE 9:e84925. doi: 10.1371/journal.pone.0084925

Zhao, L., Wang, P., Hou, H., Zhang, H., Wang, Y., Yan, S., et al. (2014). Transcriptional regulation of cell cycle genes in response to abiotic stresses correlates with dynamic changes in histone modifications in maize. PLoS ONE 9:e106070. doi: 10.1371/journal.pone.0106070

Zhao, S., and Fernald, R. D. (2005). Comprehensive algorithm for quantitative real-time polymerase chain reaction. J. Comput. Biol. 12, 1047-1064. doi: $10.1089 / \mathrm{cmb} .2005 .12 .1047$

Zhong, X., Zhang, H., Zhao, Y., Sun, Q., Hu, Y., Peng, H., et al. (2013). The rice $\mathrm{NAD}(+)$-dependent histone deacetylase OsSRT1 targets preferentially to stressand metabolism- related genes and transposable elements. PLoS ONE 8:e66807. doi: 10.1371/journal.pone.0066807

Zhou, C. H., Zhang, L., Duan, J., Miki, B., and Wu, K. (2005). HISTONE DEACETYLASE19 is involved in jasmonic acid and ethylene signaling of pathogen response in Arabidopsis. Plant Cell 17, 1196-1204. doi: $10.1105 /$ tpc.104.028514

Conflict of Interest Statement: The authors declare that the research was conducted in the absence of any commercial or financial relationships that could be construed as a potential conflict of interest.

Copyright (C) $2015 \mathrm{Su}$, Deng, Liu, Li, Hu, Zhong and Li. This is an open-access article distributed under the terms of the Creative Commons Attribution License (CC BY). The use, distribution or reproduction in other forums is permitted, provided the original author(s) or licensor are credited and that the original publication in this journal is cited, in accordance with accepted academic practice. No use, distribution or reproduction is permitted which does not comply with these terms. 